\title{
Catalytic Oxidative Conversion of Aldehydes to Carboxylic Esters and Acids Under Mild Conditions
}

\author{
Ananta Kumar Atta, Seul-Bi Kim, and Dong-Gyu Cho* \\ Department of Chemistry, Inha University, Nam-Gu Incheon 402-751, Korea. *E-mail: dgcho@inha.ac.kr \\ Received April 18, 2011, Accepted May 3, 2011
}

Key Words : Oxidative esterification, Carboxylic acids, Potassium cyanide, Benzoin condensation

Carboxylic esters have been used in pharmaceutical chemistry, materials science, and also as a protective group in organic synthesis. ${ }^{1}$ Similarly, carboxylic acids are useful synthones for the synthesis of resins, perfumes, and medicinal chemistry. ${ }^{2}$ In addition, the development of synthetic strategies toward making esters and acids is still an important area of organic synthesis. However, the most common and general strategy for the synthesis of carboxylic ester derivatives usually involves the activation of an acid followed by nucleophilic substitution (a two-step protocol). ${ }^{3}$ Alternative simple transformations have also been necessary. One of these is the direct oxidative esterification of aldehydes. Many of these reactions are currently known, and they require stoichiometric amounts of strong oxidants such as $\mathrm{Br}_{2}{ }^{4}$ $\mathrm{CrO}_{3},{ }^{5}$ hydrogen peroxide, ${ }^{6}$ ozone, ${ }^{7}$ oxone,${ }^{8} \mathrm{~N}$-iodosuccinimide, ${ }^{9}$ or expensive transition metal catalysts including but not limited to: vanadium, ${ }^{10}$ silver, ${ }^{11}$ palladium, ${ }^{12}$ ruthenium, ${ }^{13}$ rhodium, ${ }^{14}$ copper, ${ }^{15}$ titanium, ${ }^{16}$ iridium, ${ }^{17}$ and iron. ${ }^{18}$ Likewise, although there have been a few oxidative esterification reactions using organic catalysts such as $\mathrm{N}$-heterocyclic carbene (NHC), ${ }^{19}$ acetone cyanohydrin, ${ }^{20}$ or cyanide, ${ }^{21}$ these require stoichiometric amounts of either catalysts or oxidants. Furthermore, in most cases, the reactions require anhydrous and inert conditions. Therefore, the development of a mild, cost-effective, waste-minimizing method remains a worthwhile goal. In this paper, we describe a facile oxidative method for the direct conversion of aldehydes to corresponding esters (or acids) by a KCN-KI (0.2 equiv.) which does not require inert conditions and stoichiometric amounts of oxidants.

In our efforts to synthesize benzil derivatives for anion sensors, ${ }^{22}$ it was surprising that a typical benzoin condensation reaction from $\mathbf{1}$ afforded the corresponding ester $\mathbf{3}$ and acid 4 , instead of the expected benzoin product 2 , in $17 \%$, $29 \%$ yields, respectively (Scheme 1). The starting material 1 was also recovered in $53 \%$ yield. The formation of ester under the benzoin condensation condition without an apparent stoichiometric oxidant was interesting, which leads us to optimize oxidative esterification of 3,5-dimethoxybenzaldehyde as a model substrate.

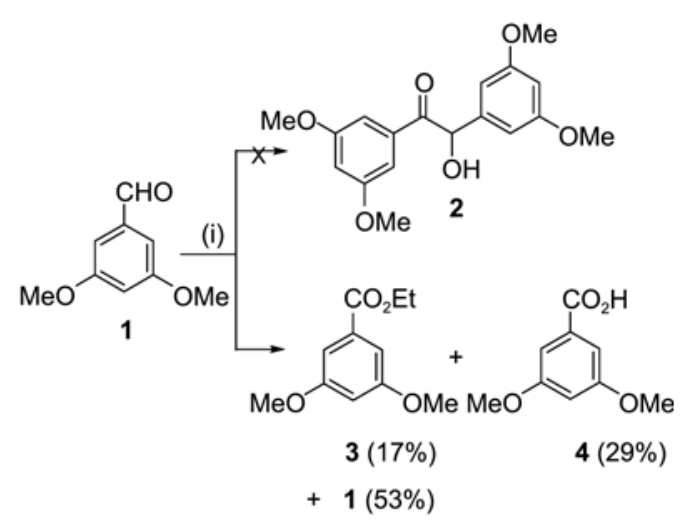

Scheme 1. Reaction conditions: (i) 2,5-dimethoxybenzaldehyde $(1.20 \mathrm{mmol}), \mathrm{KCN}(0.36 \mathrm{mmol}), \mathrm{EtOH}(6 \mathrm{~mL}), \mathrm{H}_{2} \mathrm{O}(2 \mathrm{~mL}), 80^{\circ} \mathrm{C}$, $24 \mathrm{~h}$.

Table 1. Various conditions for cyanide-mediated oxidative esterification of 3,5-dimethoxybenzaldehyde

\begin{tabular}{|c|c|c|}
\hline Entry & Reaction condition (equiv.) & Yield $(\%)^{a}$ \\
\hline 1 & $\mathrm{KCN}(0.3)$ & 36 \\
\hline 2 & $\operatorname{TBACN}(0.3)$ & 35 \\
\hline 3 & $\mathrm{KCN}(0.3), \mathrm{NIS}(0.3)$ & 3 \\
\hline 4 & $\mathrm{KCN}(0.3), \mathrm{I}_{2}(0.3)$ & trace \\
\hline 5 & $\mathrm{KCN}(0.3), \mathrm{H}_{2} \mathrm{O}_{2}(1.0)$ & trace \\
\hline 6 & $\mathrm{KCN}(0.3), \mathrm{TBAl}(0.3)$ & 71 \\
\hline 7 & $\mathrm{KCN}(0.3), \mathrm{TBABr}(0.3)$ & 37 \\
\hline 8 & $\mathrm{KCN}(0.3), \mathrm{TBAHSO}_{4}(0.3)$ & trace \\
\hline 9 & $\mathrm{KCN}(0.2)$ and $\mathrm{Kl}(0.3)$ & 71 \\
\hline 10 & $\mathrm{KCN}(0.2)$ and $\mathrm{Kl}(0.2)$ & 71 \\
\hline 11 & $\mathrm{KCN}(0.1)$ and $\mathrm{Kl}(0.1)$ & 57 \\
\hline 12 & Without $\mathrm{KCN}$ and $\mathrm{Kl}$ & 0 \\
\hline
\end{tabular}

${ }^{a}$ All reactions were carried out at $80^{\circ} \mathrm{C}$ for $24 \mathrm{~h}$ in $\mathrm{EtOH}$ without $\mathrm{N}_{2}$ or Ar. Isolated yield after column chromatographic purification. 
In the first attempt, considering the basic nature of cyanide ions in aqueous solution, carboxylic acid $\mathbf{4}$ can be formed by hydrolysis of its corresponding ester (Scheme 1). To impede the hydrolysis process, absolute EtOH was used, and the yield of ester improved to $36 \%$ (Table 1 , entry 1 ). We then carried out our trials in which oxidants were screened out in an attempt to help the reaction. Although NIS, $\mathrm{I}_{2}$, and $\mathrm{H}_{2} \mathrm{O}_{2}$ did not assist oxidative esterification (Table 1, entry 3-5), the best result was obtained with TBAI in $71 \%$ yield (Table 1 , entry 6). In some oxidation reactions, certain halogen ions are critical. ${ }^{23}$ Similarly, in this case, iodide proved to be crucial as other anions besides iodide were not nearly as effective (Table 1, entry 7-8). When cheaper KI was used, the obtained yield was the same as with tetrabutylammonium iodide (TBAI) (Table 1, entry 9). When catalyst loading was examined, 0.2 equiv. of $\mathrm{KI}$ and $\mathrm{KCN}$ seemed to be as effective as 0.3 equiv. of $\mathrm{KI}$ and $\mathrm{KCN}$ (Table 1, entry 9-11). To test the effectiveness of the KI-KCN catalyst, trials without the catalyst were conducted which did not afford its corre- sponding ester (Table 1, entry 12). Importantly, it should also be noted that, the ester cannot be obtained by oxidation of the aldehyde to a carboxylic acid followed by the simple esterification of the carboxylic acid in the presence of ethyl alcohol. When 3,5-dimethoxybenzoic acid was treated under the optimized conditions, only carboxylic acid was recovered. In addition, the best conditions under oxygen atmosphere did not produce any benign effect.

Having established these optimized conditions, we applied the methodology to a limit number of aldehydes to obtain non-volatile esters in the presence of different alcohols. The $\mathrm{KCN}-\mathrm{KI}$-catalyzed reaction occurred smoothly in both electron-withdrawing and electron-donating aldehydes (Table 2). For example, 3,5-dimethoxybenzaldehyde was reacted with ethanol, methanol, and 2-propanol separately in the presence of $\mathrm{KCN}-\mathrm{KI}$ and produced the corresponding 3,5dimethoxybenzoate in $71 \%, 59 \%$, and $48 \%$ yields, respectively (Table 2, entry 1). Also, the electron-rich 3-phenoxybenzaldehyde, with different alcohols, afforded the corre-

Table 2. KCN-KI-mediated oxidative esterification of different aldehydes

Entry

${ }^{a}$ Reactions were carried out at $80{ }^{\circ} \mathrm{C}$ for $24 \mathrm{~h}$ in appropriate alcoholic solvents without $\mathrm{N}_{2}$ or Ar. Isolated yield after column chromatographic purification.

Table 3. KCN-KI-NaOH catalyzed oxidation of aldehydes to carboxylic acids

Entry

${ }^{a}$ Isolated as its acid form. 
sponding ester derivatives in good yields (Table 2, entry 3 ). 4-cyanobenzaldehyde was also converted to the corresponding ester derivatives with methanol, ethanol, and 2-propanol (Table 2, entry 5). In all cases, the yields of ethyl esters are better than methyl or isopropyl esters.

The scope of oxidative esterification is re-examined in a one-pot reaction due to the volatile nature of esters. As shown in Table 3, strong electron-withdrawing groups facilitate the oxidative esterification, regardless of its position on benzaldehyde. However, ortho-substituted benzaldehydes may suffer from a certain steric effect that retards their ester conversion (Table 3, entry 9). In addition, furan-2-carbaldehyde afforded their corresponding esters (acids) in 53\% yield. Unfortunately, aliphatic aldehydes gave rise to unclean multiple spots on silica gel plates. Overall, although the mechanism for this oxidative esterification is not clear and being investigated in our laboratory, the catalytic effects of $\mathrm{KCN}$ and $\mathrm{KI}$ under air are apparent.

In conclusion, in typical benzoin condensation conditions the cyanide-mediated esterification of aromatic aldehydes was observed. The KCN-mediated oxidative reaction was optimized with KI, filling the gaps between benzoin condensation and oxidative esterification. This methodology not only obviates the use of stoichiometric oxidants or catalysts but also provides an alternative direct method for the synthesis of benzoate derivatives from aldehydes.

\section{Experimental Section}

General Procedure for the Synthesis of Carboxylic Esters. Absolute alcohol $(8 \mathrm{~mL})$ was added to a mixture of an aromatic aldehyde $(1 \mathrm{mmol}), \mathrm{KCN}(0.2 \mathrm{mmol})$, and $\mathrm{KI}$ $(0.2 \mathrm{mmol})$. The reaction mixture was then heated to 75-80 ${ }^{\circ} \mathrm{C}$ without $\mathrm{N}_{2}$ or Ar. After $24 \mathrm{~h}$, the solvent was evaporated to dryness under reduced pressure, yielding a residue. The residue was purified by column chromatography on silica gel (hexane/ethyl acetate $4: 1$ ) to afford the carboxylic ester. Isopropyl 3,5-dimethoxybenzoate (unknown compound): Colorless oil, IR $\left(\mathrm{CH}_{2} \mathrm{Cl}_{2}\right) 1710,1595 \mathrm{~cm}^{-1} .{ }^{1} \mathrm{H}$ NMR (400 $\left.\mathrm{MHz} \mathrm{CDCl}_{3}\right) \delta 1.29(\mathrm{~d}, J=6.4 \mathrm{~Hz}, 6 \mathrm{H}), 383(\mathrm{~s}, 3 \mathrm{H}), 5.23$ $(\mathrm{m}, 1 \mathrm{H}), 6.64(\mathrm{~m}, 1 \mathrm{H}), 7.18(\mathrm{~d}, J=2.8 \mathrm{~Hz}, 2 \mathrm{H}) ;{ }^{13} \mathrm{C} \mathrm{NMR}$ $\left(100 \mathrm{MHz}, \mathrm{CDCl}_{3}\right) \delta 22.0,55.6,68.7,105.4,107.3,133.0$, 160.8, 165.9. HRMS-ESI: $m / z[\mathrm{M}+\mathrm{Na}]^{+}$calcd for $\mathrm{C}_{12} \mathrm{H}_{16} \mathrm{O}_{4} \mathrm{Na}$ : 247.0941; found: 247.0940 .

General Procedure for the Synthesis of Carboxylic Acids. Absolute alcohol $(8 \mathrm{~mL})$ was added to a mixture of an aromatic aldehyde ( $1 \mathrm{mmol}), \mathrm{KCN}(0.2 \mathrm{mmol})$, and $\mathrm{KI}$ $(0.2 \mathrm{mmol})$. The reaction mixture was then heated to $75-80$ ${ }^{\circ} \mathrm{C}$ without $\mathrm{N}_{2}$ or Ar. After $24 \mathrm{~h}, 2 \mathrm{~mL}$ of aqueous $\mathrm{NaOH}$ (1 $\mathrm{N})$ was added to the same flask and stirred at room temperature for 1.5-2 h. Alcohol was evaporated and the residue then extracted with ethyl ether $(2 \times 10 \mathrm{~mL})$ to remove unreacted aldehydes. $\mathrm{HCl}(2 \mathrm{~N}, 10 \mathrm{~mL})$ was added to the aqueous solution and then extracted with ethyl acetate
$(3 \times 10 \mathrm{~mL})$. The combined ethyl acetate was dried over anhydrous sodium sulfate, and the solvent was concentrated under reduced pressure to produce a pure form of acids.

Acknowledgments. This work was supported by Inha University Research Grant and the Basic Science Research Program through the National Research Foundation of Korea (NRF) funded by the Ministry of Education, Science and Technology (grant no. 0741973).

\section{References}

1. (a) Greene, T. W.; Wuts, P. G. M. Protective Groups in Organic Synthesis; John Wiley \& Sons: New York, 1991. (b) Otera, J. Esterification: Methods, Reactions and Applications; Wiley: New York, 2003. (c) Ekoue-Kovi, K.; Wolf, C. Chem. Eur. J. 2008, 6302. (d) De Sarker, S.; Grimme, S.; Studer, A. J. Am. Chem. Soc. 2010, 132,1190 .

2. Mitsukura, K.; Sato, Y.; Yoshida, T.; Nagasawa, T. Biotechnol. Lett. 2004, 26, 1643.

3. Larock, R. C. Comprehensive Organic Transformations: A Guide to Functional Group Preparation; VCH: New York, 1989, p. 840 and references cited therein.

4. William, D. R.; Klingler, F. D.; Allen, E. E.; Lichtenthaler, F. W. Tetrahedron Lett. 1988, 29, 5087.

5. O'Connor, B.; Just, G. Tetrahedron Lett. 1987, 28, 3235.

6. Qian, G.; Zhao, R.; Ji, D.; Lu, G.; Qi, Y.; Suo, J. Chem. Lett. 2004, 33,834 .

7. Sundararaman, P.; Walker, E. C.; Djerassi, C. Tetrahedron Lett. 1978, 19, 1627.

8. Travis, B. R.; Sivakumar, M.; Hollist, G. O.; Borhan, B. Org. Lett. 2003, 5, 1031 .

9. McDonald, C.; Holcomb, H.; Kennedy, K.; Kirkpatrick, E.; Leathers, T.; Vanemon, P. J. Org. Chem. 1989, 54, 1213.

10. Gopinah, R.; Barkakaty, B.; Talukdar, B.; Patel, B. K. J. Org. Chem. 2003, 68, 2944.

11. Thomason, S. C.; Kubler, D. G. J. Chem. Educ. 1968, 45, 546.

12. (a) Lerebours, R.; Wolf, C. J. Am. Chem. Soc. 2006, 128, 13052. (b) Wei, L.-L.; Wei, L.-M.; Pan, W.-B.; Wu, M.-J. Synlett 2004, 1497.

13. (a) Murahashi, S.-I.; Naota, T.; Ito, K.; Maeda, Y.; Taki, H. J. Org. Chem. 1987, 52, 4319. (b) Rajendram, S.; Trivedi, D. C. Synthesis $1995,153$.

14. Grigg, R.; Mitchell, T. R. B.; Sutthivaiyakit, S. Tetrahedron 1981, 37, 4313.

15. Yoo, W.-J.; Li, C.-J. Tetrahedron Lett. 2007, 48, 1033.

16. Chavan, S. P.; Danatle, S. W.; Gavande, C. A.; Venkataraman, M. S.; Praveen, C. Synlett 2002, 267.

17. (a) Kiyooka, S.; Ueno, M.; Ishii, E. Tetrahedron Lett. 2005, 46, 4639. (b) Kiyooka, S.-I.; Wada, Y.; Ueno, M.; Yokoyama, T.; Yokoyama, R. Tetrahedron 2007, 63, 12695.

18. Wu, X.-F.; Darcel, C. Eur. J. Org. Chem. 2009, 1144.

19. (a) Schmidt, A.; Habeck, T; Snovydovych, B.; Eisfeld, W. Org Lett. 2007, 9, 3515. (b) Sakar, S. D.; Grimme, S.; Studer, A. J. Am. Chem. Soc. 2010, 132, 1190.

20. Victor Paul Raj, I.; Sudalai, A. Tetrahedron Lett. 2005, 46, 8303.

21. Castells, J.; Pujol, P. Tetrahedron 1982, 38, 337.

22. (a) Sessler, J. L.; Cho, D.-G. Org. Lett. 2008, 10, 73. (b) Cho, D.G.; Kim, J. H.; Sessler, J. L. J. Am. Chem. Soc. 2008, 130, 12163.

23. Fontaine, P.; Chiaroni, A.; Masson, G.; Zhu, J. Org. Lett. 2008, 10, 1509. 